\title{
Serial position effects in the two-choice probability learning situation
}

\section{DENNIS M. ROBERTS, DEPARTMENT OF MEASUREMENT \& EVALUATION, ONTARIO INSTITUTE FOR STUDIES IN EDU- CATION, Toronto 5, Canada AND JAMES K. BREWER,1 DEPARTMENT OF EDUCATIONAL RESEARCH AND TESTING, FLORIDA STATE UNIVERSITY, Tallahassee, Fla. 32306}

Six groups of Ss were given different length series of stimuli and then asked to recall which of two digits was predominant throughout the series. The results indicated that the probability of recall fits the typical serial position curves.

In the typical two-choice predictive situation, human Ss are required to predict which of two events, $E_{1}$ or $E_{2}$, will occur on the next trial. Brewer \& King (1968) have recently proposed a mathematical model for this situation that incorporates the serial position effect in structuring a memory decay function. In its present form, their memory function assumes that the probability of recall of an event behaves in a manner similar to the serial position curve for free recall (Deese \& Kaufman, 1957; Feigenbaum \& Simon, 1962; Murdock, 1962). Some Ss, however, do not recall the events but rather predict that event which has occurred most frequently up to the present trial, i.e., the most "predominant" event (Restle, 1961). This strategy does not appear to be the same as the recall of the event itself and would be fairly easy to follow if $\pi$-the probability of the most frequent event-was quite large. For values of $\pi$ close to .5 , however, some recall of the predominance of an event in segments of the preceding series of stimulus presentations may be necessary for the $\mathrm{S}$ to "know" which event is predominant. In the case where some recall is necessary, what is the form of the curve for probability of recall of predominance of an event in the two-choice predictive situation? This exploratory study was designed to see if the serial position effect curve would basically fit the form of the probability of recall curve.

Procedure

Six groups of college undergraduate students were used as Ss. Group size ranged from 18 to 27 with both males and females represented. The procedure was similar to what is typically used in probability learning studies. A series of 60 cards was constructed in which each card was printed with a "1" or "2." Each succeeding block of 10 cards had the same proportion $(\pi=.7)$ of 1 's. The order of 1's and 2's in each succeeding block of 10 cards was randomly determined. The Ss were instructed to predict which digit would come up on the next trial. The inter-stimulus interval of $5 \mathrm{sec}$ was manually controlled with a stopwatch. The groups were each presented with a different length series of cards ranging from 10 cards ( 1 block) in Group 1 to 60 cards ( 6 blocks) in Group 6. After each group of Ss had completed their predictions, they were asked the following question. Which digit was most predominant (occurred most often) in each block of 10 cards? For Group 1, there was only one estimate of which digit was predominant since there was only one block of 10 cards. In Group 6, however, there were six estimates corresponding to the six blocks of 10 cards each.

Results and Discussion

Figure 1 presents the results of the recorded responses. The ordinate represents the proportion of Ss who reported that the digit 1 was predominant and the abscissa represents the blocks of 10 trials. Notice that all the Ss in Group 1 recalled that the digit 1 was predominant. In Group 2, recall was also accurate for both

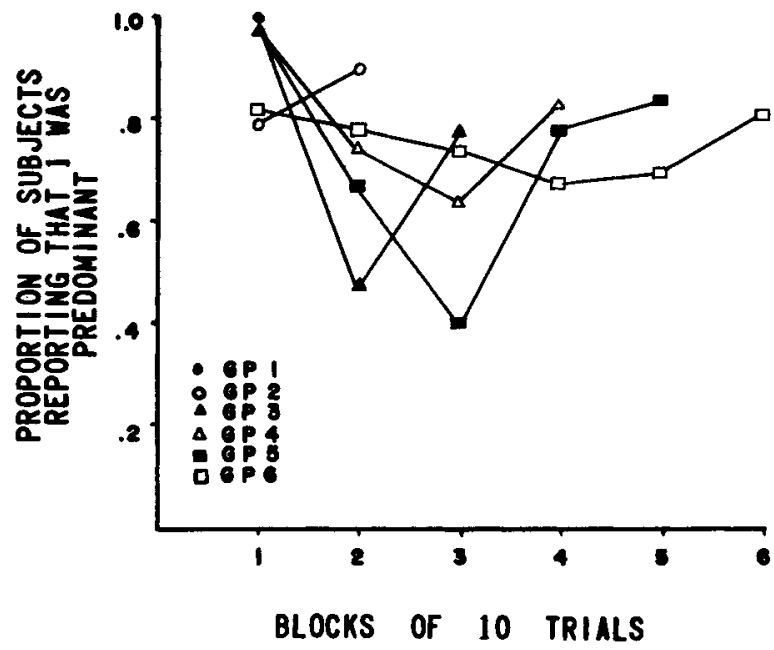

Fig. 1. Proportion of Ss reporting that the digit 1 was predominant for each block of 10 trials.

blocks of 10 cards but not as accurate as in Group 1. The most interesting data occurs for the remaining four series. A pronounced serial position curve was obtained in each of Groups 3 through 6 . Consistent with the serial position phenomenon was the occurrence of the low point of the curve just past the middle of the series. Another finding that is similar to other serial position studies was that a primacy effect was obtained, i.e., better recall in the beginning as compared with the end of the series. Since Ss were asked to recall predominance of events serially from the first block to the last block, this finding was in agreement with the results of other serial learning studies.

Although the above data were obtained from relatively small samples it does provide some evidence that the serial position effect may enter into the memory recall process in predictive situations. If Ss do, in fact, attempt to recall predominance from memory in order to make predictions, then their predictions may be affected by the serial position effect. In the area of probability learning this result seems to have one major implication. Probability learning models that assume decay-in-recall parameters could possibly be improved by including a serial position type function to account for the decay in memory.

\section{REFERENCES}

BREWER, J. K., \& KING, F. J. A note on a cognitive probability model incorporating the serial position effect. Psychometrika, 1968, 33, 249-252.

DEESE, J., \& KAUFMAN, R. A. Serial effects in recall of unorganized and sequentially organized verbal material.J. exp. Psychol., 1957, 54, 180-187.

FEIGENBAUM, E. A., \& SIMON, H. A. A theory of the serial position effect. Brit. J. Psychol., 1962, 53, 307-320.

MURDOCK, B. B., Jr. The serial position effect of free recall. J. exp. Psychol, 1962, 64, 482-488.

RESTLE, F. Psychology of judgement and choice. New York: John Wiley, 1961 .

\section{NOTE}

1. A portion of the work was completed while this author was on a NSF Science Faculty Fellowship at Stanford University. 